\title{
The risks of laparoscopic surgery: I
}

\author{
Samendra Nath Roy
}

Published online: 7 November 2006

(C) Springer-Verlag 2006

Laparoscopic surgery has been the most significant advancement in our surgical practice in recent years. The essential attribute of laparoscopic surgery is the reduction of the surgical trauma of access [6]. Therefore, laparoscopic surgery is less invasive, less disabling and less disfiguring, allowing shorter hospital stay and faster recuperation [7]. However, true to the principle that "all operations carry some risk of complications," laparoscopic surgery has its fair share of problems. An effective treatment modality always has benefits outweighing the risks. A comparative evaluation of different treatment modalities establishes the one with best benefit: risk profile as the favoured method. In light of this, I wish to critically evaluate the statement that "laparoscopic surgery is said to carry increased risk" by examining its role in present-day surgical practice. I shall also discuss how these risks can be reduced further and how to communicate the risks to our patients.

Diagnostic laparoscopy has a definitive role in the investigations of chronic pelvic pain [39], endometriosis, suspected ectopic pregnancy and infertility, as it offers the advantage of visual inspection of the abdominal and pelvic organs over imaging techniques. The notion that "laparoscopy carries increased risk" has not been proved true in the case of laparoscopic sterilisation, which is the most common laparoscopic surgery performed worldwide. A systematic review evaluating the risks and benefits of laparoscopic sterilisation compared to mini-laparotomy

This article is discussed in the editorial available at: http://dx.doi.org/ 10.1007/s10397-006-0202-4.

\section{S. N. Roy $(\square)$}

University Hospital of Hartlepool,

Holdforth Road,

Hartlepool TS24 9AH, UK

e-mail: S.N.Roy@nth.nhs.uk
[19] confirmed that the minor morbidity is significantly less following laparoscopic sterilisation and that there is no significant difference in the incidence of major morbidity associated with either method. For the surgical treatment of ectopic pregnancy, significant advantages with the laparoscopic approach have been demonstrated in many studies $[22,27,40]$ and it is the preferred option over laparotomy in haemodynamically stable patients [30]. Laparoscopy has also become an increasingly preferred approach for adenexal surgery, such as the removal of benign ovarian tumours and prophylactic bilateral salpingo-oophorectomy (BSO). A systematic review of six randomised controlled trials (RCT) confirms that, in women undergoing surgery for benign ovarian tumours, the laparoscopic approach results in less post-operative complications, including pain, pyrexia, urinary tract infection, hospital stay and total cost compared to laparotomy [25]. Patients with polycystic ovarian syndrome (PCOS), who are resistant to ovulation induction with clomiphene, show no difference in live birth and miscarriage rates compared to gonadotrophin therapy when treated with laparoscopic ovarian drilling (LOD) using diathermy or laser. LOD has a significantly lower multiple pregnancy rate and is an attractive treatment option for ovulation induction for this condition [9]. Laparoscopy remains the gold standard for the diagnosis of endometriosis [29]. Laparoscopic treatment is effective for pain relief in minimal to moderate endometriosis [14] and for minimal and mild endometriosis to improve fertility [15]. For advanced and deeply infiltrative endometriosis, radical laparoscopic excision of all diseased areas results in improvements in pain score and the quality of life [12].

The risks of surgery are proportional to its extent and complexity. There are concerns in this area as laparoscopic hysterectomy (LH) takes longer to perform and has a higher incidence of intra-operative injury to the bladder and ureter 
compared to vaginal hysterectomy ( $\mathrm{VH}$ ) and abdominal hysterectomy (AH) [17]. These disadvantages of LH were identified with a more extensive laparoscopic approach for hysterectomy. In laparoscopy-assisted vaginal hysterectomy (LAVH), when the laparoscope is used only to free the adenexal structures and the rest of the procedure (including ligation of the uterine arteries) is completed through the vaginal route, there was no significant difference in either the operation time or in the incidence of urinary tract injury compared to VH [18]. If oophorectomy is contemplated with hysterectomy, LAVH is a more appropriate method for its significant benefits over abdominal hysterectomy [18]. In gynaecological oncology, laparoscopic pelvic lymphadenectomy and radical vaginal hysterectomy has become a standard alternative to Wertheim's procedure for early-stage cancer cervix.

It is evident that, in contemporary gynaecological practice, laparoscopic surgery has a firmly established role as its benefits far outweigh its risks. Historically, laparoscopic surgery was initiated by gynaecologists and was rapidly adopted by other surgical specialities. In the developed countries, open-access cholecystectomy has virtually been abandoned in favour of laparoscopic cholecystectomy. A systematic review of 54 studies comparing laparoscopic appendectomy with conventional open-access surgery for acute appendicitis led the reviewers to recommend the laparoscopic approach for the treatment of acute appendicitis when available and affordable [35] for the significant benefits associated with it. The laparoscopic approach is adopted more and more commonly in colorectal and urological surgery for its obvious advantages.

Though laparoscopic surgery has established its firm foothold in current surgical practice, it is not without risks. A multi-centre study from France analysing the data of 29,966 procedures reported an overall complication rate $4.64 / 1,000$ and a risk of mortality of $3.3 / 100,000$ in laparoscopic procedures [5]. Laparoscopy is classed as a major procedure and, arguably, these values are not high, as all major procedures carry a $1 / 4,000$ risk of death [34]. In the French study, the risk of complications were $0.84 / 1,000$ for minor, 4.3/1,000 for intermediate and $17.45 / 1,000$ for advanced laparoscopic procedures, respectively [5]. Major complication rates following laparoscopy appear to be low [10]. Studies from Holland [16] and Finland [13] show that major complication rates following diagnostic procedures were much lower $(0.6 / 1,000$ and $2.7 / 1,000)$ than after advanced laparoscopic surgery (10.5/1,000 and 17.9/ $1,000)$. These studies show that laparoscopic surgery is generally safe and that the higher incidence of complications with advanced procedures conforms to the principle that the risks of surgery are proportional to its extent and complexity.

The majority of complications occur during the laparoscopic approach $(57 \%)$ rather than during the procedure itself (43\%) [16]. Development of pneumoperitoneum and blind entry of the first trocar poses the greatest risk of visceral injury [16]. Bowel damage, a rare $(0.4 / 1,000)$ [11], but one of most serious complications, is likely to happen particularly when the bowel is adherent to the abdominal wall. Open-access entry, though reducing the risk of injury to major vessels, is not effective in reducing injury to the structures adherent to the abdominal wall [11]. Alternatively, creating a "high-pressure" pneumoperitoneum $(25 \mathrm{~mm}$ of $\mathrm{Hg}$ ) before the first trocar entry creates a big enough air bubble to avoid injury to abdominal organs when they are not adherent to the abdominal wall [28]. In high-risk patients, where adhesions are expected, the most rational alternative is attempting entry through the Palmer's point at the left hypochondrium, which, statistically, has the least chance of adhesion formation [11]. Using "shielded trocars" and "direct viewing" trocars has not been successful to prevent serious injuries [2]. Micro-laparoscopes for the insertion of a Veress needle under vision are being developed. Radially expanding trocar sleeves allow progressive dilatation and the insertion of a 10-mm scope down the sleeve that is introduced around the Veress needle. A combination of these two technologies may reduce entry trauma to a minimum in future. However, at present, refinement of the technique rather than technology seems to be more important to reduce the risks associated with laparoscopic entry.

Interesting technological advances have been made to deliver energy safely through the laparoscope. The use of ultrasonic energy through a harmonic scalpel has the least risk of collateral damage. The development of microprocessor-controlled generators with feedback from the electrode-tissue interface to determine power output and the auto-stop facility has made use of bipolar energy even safer. However, experiences with these new devices are still at its infancy and there is not enough data to prove their "risk reduction" effectiveness.

It is important to appreciate the inherent differences between laparoscopic and open-access surgery. As the camera becomes our eyes, our brain is taught to operate in a three-dimensional space when looking at a twodimensional image. It reduces the field of vision but allows magnification of the objects. Minimal access has extended our hands to perform skill-demanding procedures with longer instruments but has taken away the tactile feedback. Technology is striving to overcome these barriers by combining three-dimensional image systems and robotics (da Vinci machine). "Hand-assisted laparoscopy" is gaining popularity. Exponential expansion of our abilities with microchips, optics, and ultrasound would, perhaps, make laparoscopic surgery safer and easier in future but at a financial cost, which, ultimately, our patients will have to bear to enjoy its advantages. Meanwhile, the risks associated with advanced laparoscopic procedures remain high. 
Risk awareness is the first step of all risk-management strategies. Laparoscopic surgery is no exception to this rule. A sizeable proportion of complications (28.6\%) remain unrecognised at laparoscopy [5]. When risk cannot be avoided totally, the next step is the early diagnosis and management of complications.

Some risk factors like extremes of age, very high or low body mass index (BMI) and associated co-morbidities are common for all surgery. The specific risk factors for laparoscopic surgery include history of previous laparotomy, presence of adhesions, intra-operative technical difficulty, level of laparoscopic complexity, suspicion of malignancy, and surgeon's experience [38]. To reduce the risk of entry-related complications, there is evidence-based advice [1]. However there is no single best method to avoid bowel injury when it is adherent to the abdominal wall. Even with experienced operators, injury during access cannot be completely avoided [3]. The experience of the operating surgeon has been identified in many studies as an important modifying factor for risks associated with laparoscopy [20, 37, 38], so it goes without saying that the surgeon and their team performing laparoscopic surgery should have adequate training and be aware of preventative steps, early recognition and the appropriate management of complications. The importance of teamwork in laparoscopic surgery cannot be over-stressed. In principle, whenever a complication is identified that cannot be dealt with laparoscopically, there should be no delay in converting to an open laparotomy and seeking the help of appropriate colleagues from other specialities.

Subcutaneous and pre-peritoneal emphysema are frequent but usually benign complications of the closed-entry technique. Palmer's test to confirm the intraperitoneal placement of the Veress needle before gas insufflation can avoid these complications. Injury to major vessels is rare $(0.2 / 1,000)$ [11] but potentially life-threatening. Following the advice of high-pressure pneumoperitoneum for "closed entry" or using an "open-access" entry technique can alleviate the risk of major retroperitoneal vascular injury (MRVI) [11, 36]. In the event of MRVI, the offending instrument should not be removed from its position. Immediate midline laparotomy and the application of a pressure pack over the injured vessel or on the aorta is advised whilst awaiting the arrival of a vascular surgeon [21]. Very rarely, Veress needle injury to a major vein and attempted $\mathrm{CO}_{2}$ insufflation may lead to gas embolism, which causes the patient to have a sudden fall in end tidal $\mathrm{CO}_{2}$ concentration, circulatory collapse and cyanosis. If suspected, further insufflation must be stopped immediately to exclude this complication.

Though the risk of bowel injury is generally low in laparoscopy $(0.4 / 1,000)$ [11], the risk increases to $33 / 1,000$ in advanced laparoscopic surgery [3]. Up to $15 \%$ of these injuries are not detected during surgery [3]. Late diagnosis of bowel injury is potentially life-threatening (mortality rate $20 \%$ ) [3]. Therefore, it is important to exercise a high index of suspicion for early detection. Following laparoscopic surgery, patients recover quickly and they are relatively free of pain [10]. If there is any deviation from this standard recovery pattern, intra-operative injury should be suspected. Bowel injury results in peritonitis with non-specific signs and symptoms. Patients presenting with persistent abdominal pain, nausea or feeling generally unwell within 2 weeks of laparoscopic surgery should be carefully observed as an inpatient and be thoroughly investigated to exclude bowel injury [21]. Injury to the bladder may result from secondary trocar insertion or from dissection during laparoscopic surgery. An indwelling catheter is advisable for advanced laparoscopic procedures. If bladder injury is suspected, this can be confirmed by a methylene blue dye test. A missed bladder perforation during laparoscopy presents with lower abdominal discomfort. Urine escapes into the peritoneal cavity and gets absorbed, producing blood biochemistry similar to that of acute renal failure. The ureters are at risk during laparoscopic hysterectomy (LH), oophorectomy or treatment of endometriosis near uterosacral ligaments. Ureteric catheterisation with transilluminating ureteric stent is practised routinely prior to $\mathrm{LH}$ in some centres. If ureteric injury is suspected during surgery, intravenous indigo carmine injection can detect any leakage of dye through the ureter. Ureteral injuries are rarely discovered intra-operatively [21]. Thermal injury to the ureter from electrosurgery may present with non-specific symptoms after several days or weeks. Patients may present with nausea, vomiting, abdominal distension, ileus and the leakage of urine through port sites. There is a characteristic rise of serum creatinine [21]. Diagnosis should be confirmed by intravenous urogram and the assistance of a urological surgeon should be sought for appropriate management. Surgeons performing electrosurgery should be fully conversant with the risks of using electrical energy, including accidental thermal spread, direct coupling and capacitative coupling, and take preventive steps to avoid them.

Effective risk communication to the patients is a legal and ethical responsibility of the doctors before performing any intervention. Patients are expected to exercise their right of "informed choice" before consenting for any intervention. Discussion prior to consenting can be viewed as a process of joint consultation between the parties (the patient and the doctor) with full knowledge and participation from both sides before agreeing to a procedure. Therefore, it is our responsibility to ensure that patients are adequately informed of the condition for which the intervention is being offered, the prognosis, likely consequences and risks of the procedure, and the risks of receiving no treatment and any alternative treatments that may be available at the time [31]. 
A qualitative study has shown that women undergoing diagnostic laparoscopy prefer to receive full and accurate information regarding possible complications, in order to make a balanced decision [26]. Ethically, it is important that the patients "substantially understand" the information presented to them before consenting for treatment [23]. Decision-making can be influenced by the way in which the information is given [8]. Therefore, the information needs to be presented in a clear unbiased manner and using language to remove any barrier in understanding. Though the majority of patients prefer the numerical presentation of information, about one third of them like verbal description [8]. The risks of an intervention can be described numerically by any of three statistical representations: "absolute risk," "relative risk" or "number needed to treat." To describe risks associated with gynaecological laparoscopic procedures, we are advised to quote "absolute risk" $[32,33]$. For the patients who prefer a verbal description of risk, it has been proposed that we use a common vocabulary as follows [4]:

Negligible A probability of below 1 in a million

Minimal Less than 1 in 100,000

Very low Less than 1 in 10,000

Low Less than 1 in 1,000

Moderate Less than 1 in 100

High A probability of greater than 1 in 100

Using this terminology, the serious risks associated with laparoscopy can be described as "low" and the risk of death as "very low."

When discussions and data can confuse patients' judgements, decision aids in the forms of leaflets, books, audio and audio-visual tapes are available for making the consenting process easier. Patients can also be educated through Web-based information away from the stress and time constraints of a consultation room.

Risk awareness has been shown to vary and there is a lack of consensus from surgeons as to which risks are significant, even for the same operation [24]. However, for most gynaecological laparoscopic procedures, the risks have been quantified and published. The background risks of a particular patient should be taken into account, along with published values to individualise risk assessment as far as possible. The discussion leading to consenting should be documented to validate the informed consent. The published consent advice from The Royal College of Obstetricians and Gynaecologists [32, 33] should provide the impetus for the hospital trusts to develop "procedure-specific" pre-printed consent forms for proper documentation.

Through the above discourse, I have shown that laparoscopic surgery has an established role in modern surgical practice. The risks with this approach cannot be described as high but are proportional to the extent and the complexity of the surgery. In future, technology is expected to make laparoscopic surgery safer. At present, risk awareness, the use of correct techniques, a high index of suspicion for early diagnosis and the treatment of complications comprise the risk reduction strategy for laparoscopic surgery. Finally, it is important that patients undergoing laparoscopic surgery should go through the process of informed consenting.

\section{References}

1. [No authors listed] (1999) A consensus document concerning laparoscopic entry techniques: Middlesbrough, March 19-20, 1999. Gynaecol Endosc 8(6):403-406

2. Bhoyrul S, Vierra MA, Nezhat CR, Crummel TM, Way LW (2001) Trocar injuries in laparoscopic surgery. J Am Coll Surgeons 192(6):677-683

3. Brosens I, Gordon A, Campo R, Gordts S (2003) Bowel injury in gynecologic laparoscopy. J Am Assoc Gynecol Laparosc 10(1):913

4. Calman K (1996) On the state of public health, 1995. HMSO, London

5. Chapron C, Querleu D, Bruhat MA, Madelnat P, Fernandez H, Pierre F, Dubuisson JB (1998) Surgical complications of diagnostic and operative gynaecological laparoscopy: a series of 29,966 cases. Hum Reprod 13(4):867-872

6. Cusheri A (1995) Minimal access surgery. In: Cusheri A, Giles GR, Moossa AR (eds) Essential surgical practice. ButterworthHeinemann, Oxford, UK, pp 1451-1462

7. Darzi A, Fowler C (1997) Minimal access surgery. In: Kirk RM, Mansfield AO, Cochrane J (eds) Clinical surgery in general: RCS course manual. Churchill Livingstone, London, UK, pp 209-212

8. Edwards A, Elwyn G (2001) Understanding risk and lessons for clinical risk communication about treatment preferences. Qual Health Care 10(Suppl I):i9-i13

9. Farquhar C, Lilford RJ, Marjoribanks J, Vandekerckhove P (2005) Laparoscopic "drilling" by diathermy or laser for ovulation induction in anovulatory polycystic ovary syndrome. Cochrane Database Syst Rev 2005(3):CD001122

10. Garry R (1997) Complications of laparoscopic entry. Gynaecol Endosc 6(6):319-329

11. Garry R (1999) Towards evidence-based laparoscopic entry techniques: clinical problems and dilemmas. Gynaecol Endosc 8 (6):315-326

12. Garry R, Clayton R, Hawe J (2000) The effect of endometriosis and its radical laparoscopic excision on quality of life indicators. Br J Obstet Gynaecol 107(1):44-54

13. Harkki-Siren P, Kurki T (1997) A nationwide analysis of laparoscopic complications. Obstet Gynecol 89(1):108-112

14. Jacobson TZ, Barlow DH, Garry R, Konickx P (2001) Laparoscopic surgery for pelvic pain associated with endometriosis. Cochrane Database Syst Rev 2001(4):CD001300

15. Jacobson TZ, Barlow DH, Konickx PR, Olive D, Farquhar C (2002) Laparoscopic surgery for subfertility associated with endometriosis. Cochrane Database Syst Rev 2002(4):CD001398

16. Jansen FW, Kapiteyn K, Trimbos-Kemper T, Hermens J, Trimbos JB (1997) Complications of laparoscopy: a prospective multicentre observational study. Br J Obstet Gynaecol 104 (5):595-600

17. Johnson N, Barlow D, Lethaby A, Tavender E, Curr E, Garry R (2005) Surgical approach to hysterectomy for benign gynaecological disease. Cochrane Database Syst Rev 2005(1):CD003677 
18. Johnson N, Barlow D, Lethaby A, Tavender E, Curr E, Garry R (2005) Methods of hysterectomy: systematic review and metaanalysis of randomised controlled trials. BMJ 330(7506):1478-1481

19. Kulier R, Boulvain M, Walker D, De Candolle G, Campana A (2005) Minilaparotomy and endoscopic techniques for tubal sterilisation. Cochrane Database Syst Rev 2004(3):CD001328

20. Leonard F, Lecuru F, Rizk E, Chassaet S, Robin F, Taurelle R (2000) Perioperative morbidity of gynecological laparoscopy. A prospective monocenter observational study. Acta Obstet Gynecol Scand 79(2):129-134

21. Li TC, Sarvelos H, Richmond M, Cooke ID (1997) Complications of laparoscopic pelvic surgery: recognition, management and prevention. Hum Reprod Updat 3(5):505-515

22. Lundorff P, Thorburn J, Hahlin M, Kalfelt B, Lindblom B (1991) Laparoscopic surgery in ectopic pregnancy: a randomized trial versus laparotomy. Acta Obstet Gynecol Scand 70(4-5):343-348

23. Majur DJ (2000) Information disclosure and beyond: how do patients understand and use the information they report they want? Med Decis Making 20(1):132-133

24. McManus PL, Wheatley KE (2003) Consent and complications: risk disclosure varies widely between individual surgeons. Ann R Coll Surg Engl 85(2):79-82

25. Medeiros LR, Fachel JMG, Garry R, Stein AT, Furness S (2005) Laparoscopy versus laparotomy for benign ovarian tumours. Cochrane Database Syst Rev 2005(3):CD004751

26. Moore J, Ziebland S, Kennedy S (2002) "People sometimes react funny if the are not told enough": women's views about the risks of diagnostic laparosopy. Health Expect 5(4):302-309

27. Murphy AA, Nager CW, Wujek JJ, Kettel MM, Torp VA, Chin HG (1992) Operative laparoscopy versus laparotomy for the management of ectopic pregnancy: a prospective trial. Fertil Steril 57(6):1180-1185

28. Phillips G, Garry R, Kumar C, Reich H (1999) How much gas is required for initial insufflation at laparoscopy? Gynaecol Endose 8 (6):369-374

29. Royal College of Obstetricians and Gynaecologists (2000) The investigation and management of endometriosis. Clinical Green Top Guideline, no. 24, July 2000. Available online at http://www. rcog.org.uk/index.asp?PageID=517
30. Royal College of Obstetricians and Gynaecologists (2004) The management of tubal pregnancy. Clinical Green Top Guideline, no. 21, May 2004. Available online at http://www.rcog.org.uk/ index.asp?Page $\mathrm{ID}=537$

31. Royal College of Obstetricians and Gynaecologists (2004) Obtaining valid consent. Clinical Governance Advice, no. 6, October 2004. Available online at http://www.rcog.org.uk/index. asp?PageID $=478$

32. Royal College of Obstetricians and Gynaecologists (2004) Diagnostic laparoscopy. Consent Advice, no. 2, October 2004. Available online at http://www.rcog.org.uk/index.asp? PageID $=1629$

33. Royal College of Obstetricians and Gynaecologists (2004) Laparoscopic tubal occlusion. Consent Advice, no. 3, October 2004. Available online at http://www.rcog.org.uk/index.asp? PageID $=1630$

34. Royal College of Obstetricians and Gynaecologists (2004) Abdominal hysterectomy for heavy periods. Consent Advice, no. 4, October 2004. Available online at http://www.rcog.org.uk/ index.asp?PageID $=1627$

35. Saurland S, Lefering R, Neugebauer EAM (2004) Laparoscopic versus open surgery for suspected appendicitis. Cochrane Database Syst Rev 2004(4):CD001546

36. Saville LE, Woods MS (1995) Laparoscopy and major retroperitoneal vascular injuries (MRVI). Surg Endosc 9(10):1096-1100

37. Shen CC, Wu MP, Kung FT, Huang FJ, Hsieh CH, Lan KC, Huang EY, Hsu TY, Chang SY (2003) Major complications associated with laparoscopic-assisted vaginal hysterectomy: tenyear experience. J Am Assoc Gynecol Laparosc 10(2):147-153

38. Sokol AI, Chaung K, Milad MP (2003) Risk factors for conversion to laparotomy during gynecologic laparoscopy. J Am Assoc Gynecol Laparosc 10(4):469-473

39. Stones W, Cheong YC, Howard FM (2005) Interventions for treating chronic pelvic pain in women. Cochrane Database Syst Rev 2005(2):CD000387

40. Varmesh M, Silvia PD, Rosen GF, Stein AL, Fossum GT, Sauer MV (1989) Management of unruptured ectopic gestation by linear salpingostomy: a prospective, randomized clinical trial of laparoscopy versus laparotomy. Obstet Gynecol 73(3 Pt 1):400-404 